\title{
Earthquake Vulnerability Reduction Program in Colombia A Probabilistic Cost-benefit Analysis
}

\author{
Francis Ghesquiere, World Bank \\ Luis Jamin, University of Los Andes \\ Olivier Mahul, World Bank ${ }^{1}$
}

\begin{abstract}
Cost-benefit analysis is a standard tool for determining the efficiency of planned projects. However, one of the major difficulties in risk mitigation investments is that benefits are by nature uncertain. In this context, the standard approach relying on the average value of benefits may provide an incomplete picture of the efficiency of the risk mitigation project under consideration. This paper presents a probabilistic cost-benefit analysis relying on a catastrophe risk model. It produces risk metrics such as the exceedance probability curve of the benefit-cost ratio, thus providing the decisionmaker with a more complete risk analysis of the net benefits of the project. This is illustrated with the earthquake vulnerability reduction project in Colombia.
\end{abstract}

Key words: Colombia, cost-benefit analysis, disaster risk management, earthquake, probabilistic risk models.

World Bank Policy Research Working Paper 3939, June 2006

The Policy Research Working Paper Series disseminates the findings of work in progress to encourage the exchange of ideas about development issues. An objective of the series is to get the findings out quickly, even if the presentations are less than fully polished. The papers carry the names of the authors and should be cited accordingly. The findings, interpretations, and conclusions expressed in this paper are entirely those of the authors. They do not necessarily represent the view of the World Bank, its Executive Directors, or the countries they represent. Policy Research Working Papers are available online at http://econ.worldbank.org.

\footnotetext{
${ }^{1}$ Corresponding author: MC 9-904; 1818 H Street, NW; Washington, D.C. 20433. Phone: (202) 458-8955. Email: omahul@worldbank.org.
} 


\section{Introduction}

Due to its location, Colombia is highly prone to natural disasters. The country strides the Andean mountain region and the Pacific "belt of fire," where high seismic potential combines with volcanic activity. In the last 25 years, the country has suffered six major earthquakes, three volcanic eruptions, major landslides, avalanches, petroleum and chemical explosions/leaks, and extensive flooding. With major cities located in areas of elevated risk, combined with the high rate of urbanization, Colombia is extremely vulnerable to adverse natural events. This vulnerability is further aggravated by continued population growth and the ever increasing concentration of settlements and assets. Recent trends in global climate change followed by rising climatic variability will likely exacerbate the country's exposure to floods, erosion, landslide, and drought.

The need for a more comprehensive disaster risk management approach became clear following the devastating earthquake in Popayan in 1983. At that time, the Government of Colombia established the National System for Disaster Response and Prevention, shifting emphasis to a broader disaster risk management approach and a strategy focused on risk identification, risk reduction, and risk transfer. In particular, Parliament passed Law 400 in August 1997, which established seismic-resistant building standards for new construction and a timeline for the retrofitting of key public facilities such as hospitals and fire stations that would be needed to provide critical services during and after emergencies. The World Bank, which has been actively supporting this proactive approach through a series of projects, is helping the Capital District of Bogotá in the financing of a comprehensive Disaster Vulnerability Reduction Project. This project aims at reducing the District's vulnerability to adverse natural events by strengthening national capacity to manage disaster risk and by reducing vulnerability in key municipalities.

Located in a region of Colombia prone to earthquakes, floods, and landslides, accommodating 7 million inhabitants and responsible for one-fourth of national gross domestic product, Bogotá DC has by far the largest concentration of risks in the country. Recent modeling exercises estimate that a 1-in-100-year earthquake in Bogotá DC could generate losses of about US $\$ 5$ billion. Earthquakes with return periods of 200 years and 500 years could result in losses in excess of US $\$ 25$ billion and US $\$ 47$ billion, respectively (Cardona 2005). Such a disaster would have serious socioeconomic repercussions in terms of both human welfare and the overall impact on the national economy.

Bogotá DC already has many important elements of a disaster management system. A decree established in October 2004 the System for Prevention and Response to Emergencies (SDPAE) in Bogotá DC. The system is coordinated by the Directorate for the Prevention of and Attention to Emergencies (DPAE), which brings together diverse public, private, and community actors involved in risk management under the leadership of the new mayor. 
The World Bank has a long history of financing disaster response, emergency recovery projects around the world. The Bank has disbursed about US\$40 billion in emergency and reconstruction loans (ERLs) over the last 20 years, with 23 percent of these ERLs provided to Latin American and Caribbean countries. Recently, however, more attention has been given to mitigation programs aimed at enhancing governmental capacity to respond to disasters and reduce their risk vulnerability. Recent Bank-assisted projects in Colombia, Honduras, and Turkey have pioneered methodologies for integrating risk analysis into urban and regional development planning, and for evaluating risk reduction measures as economic investments in urban and regional investment programs.

A standard tool for determining the costs and benefits, and thus the efficiency, of planned projects is cost-benefit analysis. It compares the costs of implementing such projects with its benefits and calculates a net present value for the investment (or alternatively, the economic rate of return or the benefit-cost ratio). However, one of the major difficulties in risk mitigation investments is that benefits are by nature uncertain because they depend on the occurrence of a natural disaster. In this context, the standard approach relying on the average annual value of benefits does not capture the uncertainty related to the occurrence of a catastrophic event. In particular, this analysis fails to capture much of the information generated by sophisticated probabilistic catastrophe risk models.

To correct this shortcoming, the methodology proposed by this paper estimates the distribution function of the benefit-cost ratio of mitigation investments. It uses the statistical outputs produced by the probabilistic risk models in the cost-benefit analysis, through the development of a microeconomic probabilistic cost-benefit analysis. In particular, this model produces the loss exceedance curve of the benefit-cost ratio of the planned mitigation project. It thus offers decisionmakers additional valuable information related to the economic viability of the risk mitigation project under consideration. Such information provides the decisionmaker with, for instance, the probability that the project will be viable over a given time period. As such, the paper proposes expanding the standard cost-benefit analysis, which focuses only on the expected values produced, by taking into account the underlying distribution function of the technical variables.

The proposed methodology is illustrated with the earthquake vulnerability reduction project implemented by the Government of Colombia, with the technical and financial assistance of the World Bank. The model shows that this US\$160 million earthquake mitigation project is economically viable, given the high country exposure to earthquakes, because the average benefit-cost ratio is higher than unity.

\section{Probabilistic Cost-benefit Analysis}

Estimating project costs for the prevention or mitigation of the effects of a natural disaster is generally straightforward. Estimating projected benefits of prevention investments, however, is more complicated. First, it is not possible to predict when an actual disaster event will occur and with what intensity. Second, the effectiveness of mitigation investments is estimated through vulnerability assessments that include a degree of uncertainty. Therefore, in disaster mitigation projects, while costs are well 
defined, benefits derived from likely or avoided losses are not definitive, but are rather probabilistic, at best.

A macroeconomic approach is pertinent for mitigation projects when micro-level data are unavailable or unreliable. Macroeconomic calculations include not only retrofitting investments but also emergency preparedness investments. This approach was adopted in the Istanbul Seismic Risk Mitigation and Emergency Preparedness Project in Turkey financed by the World Bank. Under the Bogotá Disaster Vulnerability Reduction Program, structural and functional investments in public buildings account for about 90 percent of the overall project costs. In addition, the project benefits are assessed through a sophisticated earthquake-risk-assessment model developed under this project. In this context, a probabilistic microeconomic approach for performing cost-benefit analysis, focusing on key earthquake mitigation investments, is proposed. It relies on a costbenefit analysis combined with a probabilistic earthquake-risk-assessment model.

\section{Probabilistic Earthquake Risk Model}

The assessment of catastrophe risk is significantly different from the evaluation of risks of automobile collisions or fires. The severity of the former is higher because the causative events are large scale and affect hundreds of square kilometers, sometimes impacting hundreds of thousands of properties. Since the frequency of disaster events is particularly low, historical data are not adequate to measure potential losses. Therefore, risk assessments need to be prospective, anticipating scientifically credible events that might happen in the future. Using current computer technology and modern earth science information, models of earthquakes have been developed by specialized firms for use by insurers, re-insurers, and government agencies to assess the risk of loss as a result of a catastrophic event. Since large uncertainties are inherent in model estimates with regard to event severity and frequency characteristics in addition to consequent losses caused by such events, models often are constructed using probabilistic formulations that incorporate this uncertainty into the risk assessment.

The model, built upon a sequence of modules, quantifies potential losses arising from a given hazard (for example, earthquake), as shown in Figure 1.

Figure 1. Probabilistic Catastrophe Risk Model

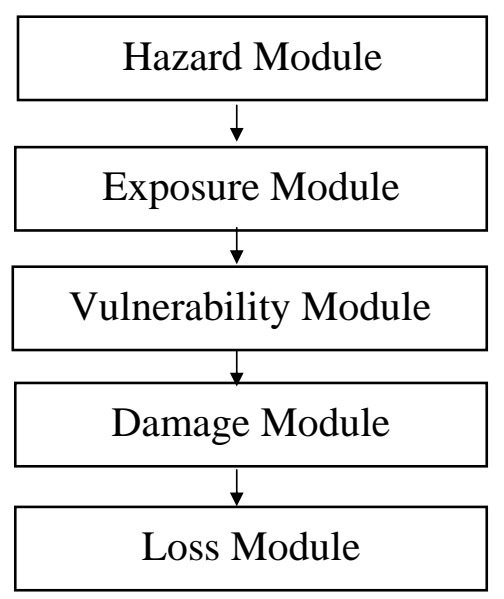


Hazard module. The hazard module defines the frequency and severity of a peril, at a specific location. This is done by analyzing the historical event frequencies and reviewing scientific studies performed on the severity and frequencies in the region of interest. Once the hazard parameters for each peril are established, stochastic event sets are generated that define the frequency and severity of thousands of stochastic cyclone or flooding events. This module can analyze the intensity at a location once an event in the stochastic set has occurred. This module models the attenuation/degradation of the event from its location to the site under consideration and evaluates the propensity of local site conditions to either amplify or reduce the impact.

Exposure module. The exposure values of "assets at risk" are estimated either from available secondary data sources or are derived from the distribution of population. This "proxy" approach is used when the preferred specific site-by-site data are not available. Based on these data, the module then computes the value for all types of exposures as a product of multiplication of the area of total building inventory and the average replacement cost per unit of inventory.

Vulnerability module. The module quantifies the damage caused to each asset class by the intensity of a given event at a site. The development of asset classification is based on a combination of construction material, construction type (wall and roof combination, for example), building usage, number of stories, and age. Estimates of damage are measured in terms of a mean damage ratio (MDR). The MDR is defined as the ratio of the repair cost divided by the replacement cost of the structure. The curve that relates the MDR to the earthquake intensity is called a vulnerability function. Each asset class and building type will have different vulnerability curves for each peril.

Damage module. To calculate losses, the damage ratio derived in the Vulnerability module is translated into dollar loss by multiplying the damage ratio by the value at risk. This is done for each asset class at each location. Losses are then aggregated as required.

Loss module. This module estimates the losses to the insurer from the damage distribution, based on the insurance information (for example, deductible, sum insured).

Building upon a sequence of the five modules, the model quantifies potential losses that might arise as a result of an earthquake. Risk metrics produced by the model provide risk managers and policymakers with essential information necessary to manage future risks. One measure is called the Average Annual Loss and the other is the Loss Exceedance Probability. Other measures based on these two metrics are the Pure Risk Premium and the Probable Maximum Loss.

Average Annual Loss (AAL). AAL is the expected loss per year when averaged over a very long period (for example, 500 years). Computationally, AAL is the summation of products of event losses and event occurrence probabilities for all stochastic events in a loss model. The events are an exhaustive list affecting the location/region under consideration, generated by stochastic modeling. In probabilistic terms, the AAL is the mathematical expectation. 
Pure Risk Premium (PRP). PRP equals the AAL divided by the replacement value of the asset, usually expressed as a rate per mill of monetary value.

Loss Exceedance Curve (LEC). This represents the probability that a loss of any specified monetary amount will be exceeded in a given year. This is the most important catastrophe risk metric for risk managers, since it estimates the amount of funds required to meet risk management objectives. The LEC can be calculated for the largest event in one year or for all (cumulative) events in one year. For risk management purposes, the latter estimate is preferred, since it includes the possibility of one or more severe events resulting from, for example, earthquakes and/or floods.

Probable Maximum Loss (PML). PML is a subset of the LEC value, which represents the loss amount for a given probability or return period, per year. Depending on an organization's risk tolerance, the risk manager may decide to manage for losses up to a certain return period (for example, 1 in 300 years). For that organization, the PML is the 300-year loss. For others, it may be 150 years, or for others 500 years. It is noteworthy that the general industry norm is to set program insolvency at the 1-in-150-year level to 1-in-200-year level, which roughly corresponds to the level of solvency required for $\mathrm{BBB}+$ companies rated by Standard \& Poor's.

\section{Nature of Cost-benefit Analysis}

Cost-benefit analysis (CBA) is a systematic procedure for evaluating decisions that have an impact on societies. A CBA is conducted depending on available information. Following Smyth and others (2003), a simplified five-step procedure is described below.

Step 1: Specify the nature of the problem. Options have to be specified. One alternative is the status quo. In the current analysis, the status quo refers to the current vulnerability of the structure without any mitigation measures. This alternative is usually the reference point to illustrate how well other alternatives perform.

Step 2: Determine the direct costs of mitigation measures. For each mitigation alternative, the direct costs to implement the mitigation measure are specified. If these costs are financed through a loan, the cost of capital should also be included.

Step 3: Determine the benefits of mitigation alternatives. Probabilistic risk modeling techniques are used to simulate the impact of catastrophic events (for example, earthquakes). The status quo reflects the expected damage to the building without mitigation. With respect to each of the mitigation measures, the expected benefits are estimated as the reduction in damage to the building as a result of a catastrophic event (with varying magnitudes), relative to the status quo. In addition to reducing physical damage to key social infrastructure, there are additional benefits of mitigation works such as lessening the number of fatalities or injuries caused by the event. Other benefits may include costs of business interruption. These costs may be significant in the case of lifeline infrastructure like hospitals. 
Step 4: Calculate attractiveness of mitigation alternatives. The attractiveness of mitigation is calculated as the difference between the benefits to each interested party and the upfront costs of mitigation. With respect to lifelines, the alternatives involve a degree of outage or serviceability over a defined time horizon. The social discount rate is then used to convert future benefits and costs into a net present value (NPV) or benefit-cost $(\mathrm{B} / \mathrm{C})$ ratio. A mitigation measure is considered attractive if the NPV is positive or, equivalently, if the $\mathrm{B} / \mathrm{C}$ ratio is higher than unity.

Step 5: Choose the best mitigation alternative. The best alternative among mutually exclusive mitigation alternatives is the one with the highest NPV or, equivalently, the highest $\mathrm{B} / \mathrm{C}$ ratio.

\section{Application to the Bogotá Disaster Vulnerability Reduction Program}

The World Bank-financed Bogotá Disaster Vulnerability Reduction Project is a five-year project with a World Bank loan of US\$80 million, and a contribution of US\$80 million from the District of Bogotá. The purpose of this project is to reduce the city's exposure to adverse natural events by strengthening local capacity to manage disaster risk and reduce vulnerability of key infrastructure. By the time of program completion both physical and financial vulnerability to adverse natural events should be measurably reduced.

This project addresses five lines of action outlined in the city's 10-year plan: (a) risk identification, (b) risk reduction, (c) institutional strengthening, (d) risk prevention and awareness, and (e) financial coverage.

The objective of the Risk Identification component is to enhance the capacity of the District of Bogotá to identify and monitor risks. The component will help the District better target its investments and identify potential calamities before they occur. Activities include studies for hazard identification (for example, floods, geotechnical and seismic risks), vulnerability assessments (for example, assessment of substandard housing and public buildings), and risk management (for example, probability of loss of life when vulnerability is not addressed), and studies for hazard mapping, which involve equipment identification to gather information on earthquakes, floods, and landslides.

The Risk Reduction component aims to complement the city's existing risk reduction efforts to reduce the vulnerability of critical facilities and lifeline infrastructure. The purpose of this component is to save lives by ensuring the continued functioning of such facilities in the event of adverse natural or technological catastrophe. The component also supports the implementation of nonstructural and functional mitigation measures for the continuity of service during and after emergencies. Activities under this component include seismic mitigation through the development of engineering designs and retrofitting or construction works for public buildings to meet the latest seismic standards as defined in Law 400, including hospitals, schools, and fire stations. 
The purpose of the Institutional Strengthening component is to enhance the effectiveness and capacity of the District Administration to prepare for, respond to, and recover from significant emergencies. In this context, the component also supports the strengthening of the District's capacity to implement the project.

The Risk Prevention and Awarenes component aims to increase awareness at all levels of society, and in particular, at the community level in order to convey the importance of risk mitigation and disaster preparedness.

The objective of the Financial Coverage component is to develop a risk financing strategy for losses arising from natural disasters. It aims to provide the Municipality of Bogotá DC with a financial strategy to ensure the availability of resources for relief, early recovery, rehabilitation, and reconstruction, should a major disaster occur. It also aims to facilitate the development of a private catastrophe insurance market, based on recent experiences in Colombia.

\section{Earthquake Risk Model}

A probabilistic earthquake risk assessment model for the city of Bogotá DC was developed to assess the earthquake risk exposure of a portfolio of public buildings in Bogotá District. This model relies on a micro-zonation of Bogotá DC and applies the most advanced simulation techniques on ground motion description, structural modeling, and computation of structural response. ${ }^{2}$ A sample of 388 buildings was randomly chosen (including 63 fire stations, 65 hospitals, 9 schools, and 251 administrative buildings; see Figure 2) for further analysis. The value at risk of these buildings is estimated at US\$1,383 million.

\footnotetext{
${ }^{2}$ The description of the probabilistic seismic loss estimation methodology is beyond the scope of this paper. It can be found in Jamin (2005).
} 


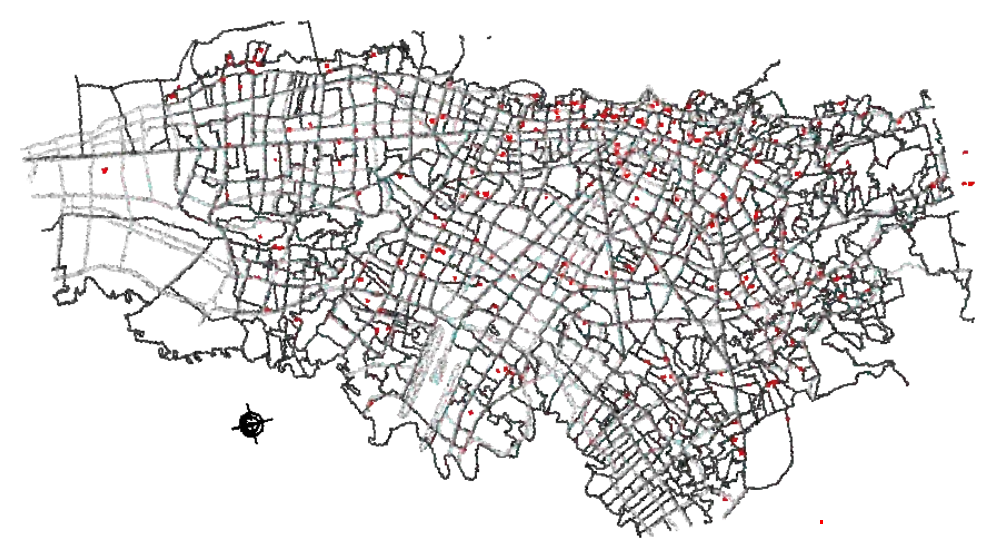

Source: Jamin (2005).

The project finances hazard risk mitigation measures. These interventions are structural, nonstructural, and functional. Structural mitigations encompass basic reinforcements to existing buildings, while nonstructural interventions consist of the resettlement of vulnerable populations in high-risk areas. Finally, functional mitigation involves the protection of people and assets, so that they remain functional during and immediately after an emergency (this involves such tasks as contingency planning, business continuity planning, emergency access, safeguarding of equipment, and so forth). Specifically, these measures aim to ensure that any damage resulting from an adverse event is limited enough to preclude evacuation of vital buildings such as hospitals, while understanding that the disruption of some noncrucial functions may be unavoidable.

The analysis shows that structural investments have a significant impact on the infrastructure resilience to earthquakes. On the portfolio of selected public assets, the pure premium is estimated to decline from 7.4 per mill to 1.5 per mill once the buildings are retrofitted. Figure 3 shows the benefits of structural investments for the selected public buildings. 
Figure 3. Pure Risk Premiums, before and after Structural Investments

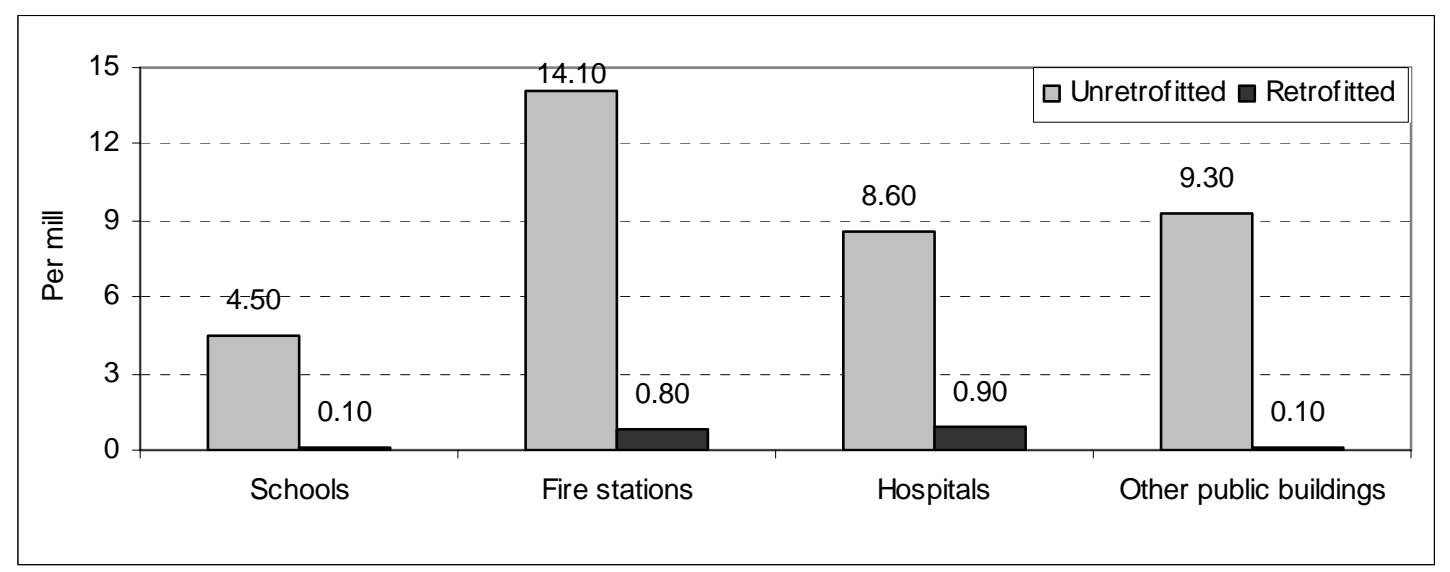

The benefits of the structural investments can also be captured through the reduction in PML of an earthquake event with a 1-in-1000 year return period on the portfolio of selected public buildings (see Figure 4). If such an earthquake were to hit the city, the resulting losses to school buildings would decrease from 30 percent to 4 percent of their asset value if they were retrofitted.

Figure 4. PML of 1-in-1000 year Earthquake Event, before and after Structural Investments

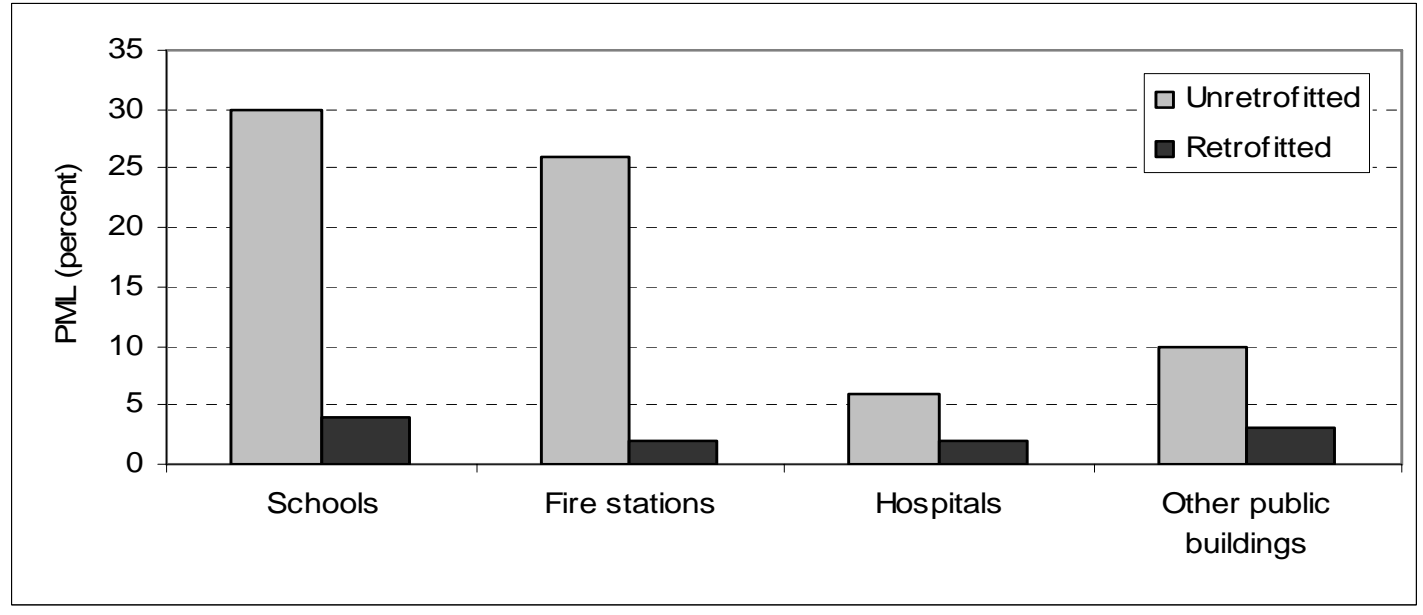

The loss exceedance curves of the portfolio of public assets before and after structural investments are depicted in Figure 5. This program would significantly reduce the potential losses caused by earthquakes. For example, a 1-in-500-year earthquake is estimated to cause losses of up to 9.2 percent of the value of unretrofitted buildings, while the structural program would reduce these losses to 3.8 percent. It is noteworthy that the benefits of these structural investments are also significant for more frequent events: the probable maximum loss (PML) of a 1-in-100-year earthquake decreases from 6.1 percent to 2.2 percent. 


\section{Figure 5. Loss Exceedance Curves of Portfolio of Selected Public Buildings, before and after Structural Investments}

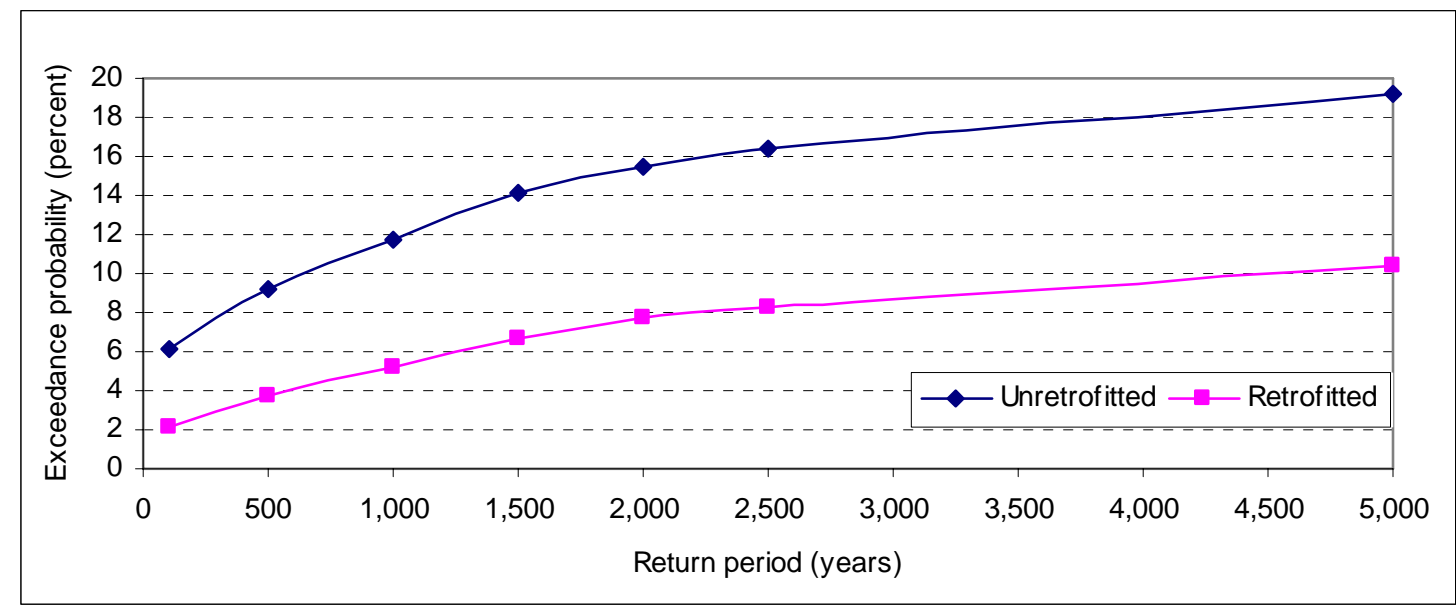

\section{Probabilistic Cost-benefit Analysis of the Risk Mitigation Project}

Approximately US $\$ 160$ million has been earmarked for the structural and functional strengthening of 134 schools (including kindergartens), 32 hospitals, and 2 fire stations. Risk mitigation measures under this project are planned to be implemented within a fouryear period. The time horizon of this project is 30 years, which is less than the average lifetime of a standard building.

The average annual return on mitigation investment is defined by

$$
\bar{R}^{i}=\frac{\bar{L}_{w / o}^{i}-\bar{L}_{w}^{i}}{I^{i}}
$$

where $i$ is the type of mitigation investment (structural, structural and functional), and $\bar{L}_{w / o}^{i}\left(\bar{L}_{w}^{i}\right)$ is the annual average earthquake loss before (after) mitigation investment and $I^{i}$ is the investment amount.

Simulations from the probabilistic earthquake risk assessment model show that structural investments generate an average annual return equal to 14.5 percent for retrofitted schools and 19.1 percent for retrofitted hospitals and fire stations (see Table 1). This means that a US $\$ 100$ investment will reduce the average annual property loss caused by an earthquake by US\$14.5 for schools and by US\$19.1 for hospitals and fire stations.

Structural and functional investments not only provide for reduction in property losses, but may also save lives and reduce the number of injuries. ${ }^{3}$ In the case of an earthquake

\footnotetext{
${ }^{3}$ Most conventional cost-benefit models assign a monetary value to human life, which commands a much greater monetary amount than property. Based on recent studies, the value of a statistical life in Colombia
} 
with a return period of 50 years, these risk mitigation investments are assumed to save about 5,000 lives (1,000 lives in schools and 4,000 lives in hospitals) and avoid about 50,000 injuries. Lives saved in hospitals and fire stations include not only direct-saved lives (that is, people staying at the hospital at that time), but also indirect saved lives (that is, lives saved because hospitals and fire stations are able to provide emergency service to the affected population in the aftermath of the earthquake). Under these assumptions, the average annual return of structural and functional investments is estimated at 7.7 percent for schools and 32.8 percent for hospitals and fire stations (see Table 1). These high returns highlight the high (average) monetary benefits generated by these mitigation investments.

Table 1. Average Annual Returns on Mitigation Investments

\begin{tabular}{lcc}
\hline & $\begin{array}{c}\text { Structural } \\
\text { Investments }\end{array}$ & $\begin{array}{c}\text { Structural and Functional } \\
\text { Investments }\end{array}$ \\
Schools & $14.5 \%$ & $7.7 \%$ \\
Hospitals and Fire Stations & $19.1 \%$ & $32.8 \%$ \\
\hline
\end{tabular}

\section{Mitigation Measures Outweigh Costs}

A model was developed to carry out the probabilistic cost-benefit analysis. It computes the net present value, the economic rate of return, and the benefit-cost ratio (that is, NPV of benefits / NPV of costs) of the risk mitigation investments (see annexes). It relies on the following expressions:

$$
\begin{aligned}
& N P V\left(\text { Benefits }^{i}\right)=\left[\bar{L}_{w / o}^{i}-\bar{L}_{w}^{i}\right]\left[\frac{1}{4(1+d)}+\frac{1}{2(1+d)^{2}}+\frac{3}{4(1+d)^{3}}+\sum_{t=4}^{30}(1+d)^{-t}\right] \\
& N P V\left(\text { Cost }^{i}\right)=\frac{I^{i}}{4}\left[1+\frac{1}{(1+d)}+\frac{1}{(1+d)^{2}}+\frac{1}{(1+d)^{3}}\right]
\end{aligned}
$$

where $i$ is the type of mitigation investment, $\bar{L}_{w / o}^{i}\left(\bar{L}_{w}^{i}\right)$ is the average annual earthquake loss before (after) the mitigation investment, $I^{i}$ is the amount of the mitigation investment, and $d$ is the discount factor.

Figure 6 shows the average economic rate of return (ERR) of structural investments and the ERR of structural and functional (S\&F) investments. Under the above assumptions (scaling factor is 1), the ERR of the structural investment is estimated as 16.6 percent, while the ERR of the S\&F investments is estimated at 20.2 percent. They are well above the discount factor of 12 percent suggested as a reference in the World Bank projects, meaning that this project is economically viable.

is assumed to be US\$500,000. This approach is conservative. A higher value would of course increase the monetary benefits of the project. 
A basic sensitivity analysis is also performed because the potential benefits of such investments are highly uncertain. A scaling factor is applied to the avoided average annual losses (that is, benefits). The scaling factor ranges from 1.0 to 0.6 , that is, the benefits of this project are reduced by 10 percent to 40 percent. For example, a scaling factor of 0.8 means that average annual benefits are reduced by 20 percent. Figure 6 shows that the ERR of the S\&F investments is always higher than the ERR of the structural investments, whatever the scaling factor. It decreases from 20.2 percent to 10.8 percent if the average annual benefits are reduced by 40 percent. Therefore, with a discount factor of 12 percent, the earthquake risk mitigation project is economically viable (that is, the ERR is higher than 12 percent), even when the average benefits are reduced by up to 30 percent.

Figure 6. Economic Rate of Return (ERR) of Structural Investments and Structural and Functional Investments

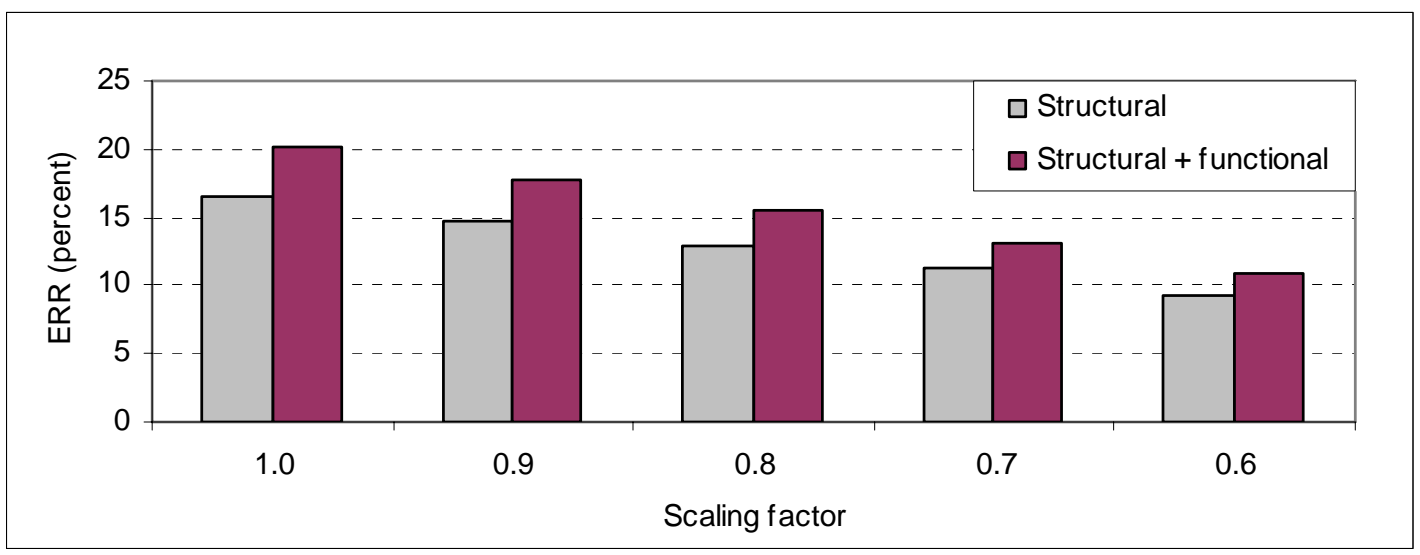

Note: The scaling factor is a multiplier coefficient applied to the average annual benefits of the risk mitigation project to take into account the uncertainty around these potential benefits.

\section{Benefit-cost Ratios with Financing Structure}

The above analysis takes into account only the costs and average annual benefits generated by the project. Other costs and benefits come from the financing structure of this project. This project is financed with a US $\$ 80$ million loan financed by the World Bank and US\$80 million in bonds issued by the District of Bogotá on the financial markets. 
Table 2 describes the cost of financing used in this analysis.

Table 2. Financial Assumptions

\begin{tabular}{lcc}
\hline & WB Loan & Other Loan \\
Front-end Fees & $0.5 \%$ & no \\
Commitment Fees & $0.35 \%$ & no \\
Grace Period & 5 years & no \\
Maturity & 17 years & 11 years \\
Average Interest Rate & $3 \%$ & $8 \%$ \\
\hline
\end{tabular}

The net present value of the cost of the project becomes

$$
\begin{aligned}
N P V\left(\text { Cost }^{i}\right)= & I_{W B}^{i}\left[\operatorname{FEF}+C F\left(\frac{3}{4(1+d)}+\frac{1}{2(1+d)^{2}}+\frac{1}{4(1+d)^{3}}\right)+\sum_{t=6}^{17} \frac{\hat{I}_{W B}^{i}}{(1+d)^{t}}\right] \\
& +I_{O B}^{i} \sum_{t=1}^{11} \frac{\hat{I}_{O B}^{i}}{(1+d)^{t}}
\end{aligned}
$$

where FEF is the front-end fees paid on the total amount, CF is the commitment fees paid on the undisbursed amount, $I_{W B}^{i}$ is the loan amount borrowed from the World Bank, and $I_{O B}^{i}$ is the loan amount borrowed from another credit institution, with $I_{W B}^{i}+I_{O B}^{i}=I^{i}$. $\hat{I}_{W B}^{i}$ satisfies

$$
\hat{I}_{W B}^{i} \sum_{t=6}^{17}\left(1+i_{W B}\right)^{-t}=\frac{I_{W B}^{i}}{4}\left[1+\left(1+i_{W B}\right)^{-1}+\left(1+i_{W B}\right)^{-2}+\left(1+i_{W B}\right)^{-3}\right]
$$

where $i_{W B}$ is the annual average interest rate charged by the World Bank. $\hat{I}_{O B}^{i}$ satisfies

$$
\hat{I}_{W B}^{i} \sum_{t=1}^{11}\left(1+i_{O B}\right)^{-t}=\frac{I_{O B}^{i}}{4}\left[1+\left(1+i_{O B}\right)^{-1}+\left(1+i_{O B}\right)^{-2}+\left(1+i_{O B}\right)^{-3}\right]
$$

where $i_{O B}$ is the annual interest rate charged by the other credit institution.

The benefit-cost $(\mathrm{B} / \mathrm{C})$ ratio of the structural and functional investments is estimated with a discount factor of 12 percent. ${ }^{4}$ The analysis shows a positive rate of return for the project even without the favorable terms offered by the World Bank. Indeed, Figure 7

\footnotetext{
${ }^{4}$ This discount factor is used to evaluate the economic and financial viability of all World Bank projects. However, some economists suggest using declining discount rates for impacts that occur further in the future in order to reflect the concern with future generations (Cropper, Aydede, and Portney 1992).
} 
shows an increase of the $\mathrm{B} / \mathrm{C}$ ratio for the project from 1.6 to 2.5 if the favorable terms offered by the World Bank are taken into account. A sensibility analysis shows that the project would still be economically viable if the average benefits are reduced by 40 percent. In other words, the proposed investments would still have an economic rate of return higher than 12 percent even if the average benefits of the project were reduced by 40 percent, thanks to the friendly financing conditions offered by the World Bank.

\section{Figure 7. Benefit-cost Ratio of Structural and Functional Investments with and without Loan Financing}

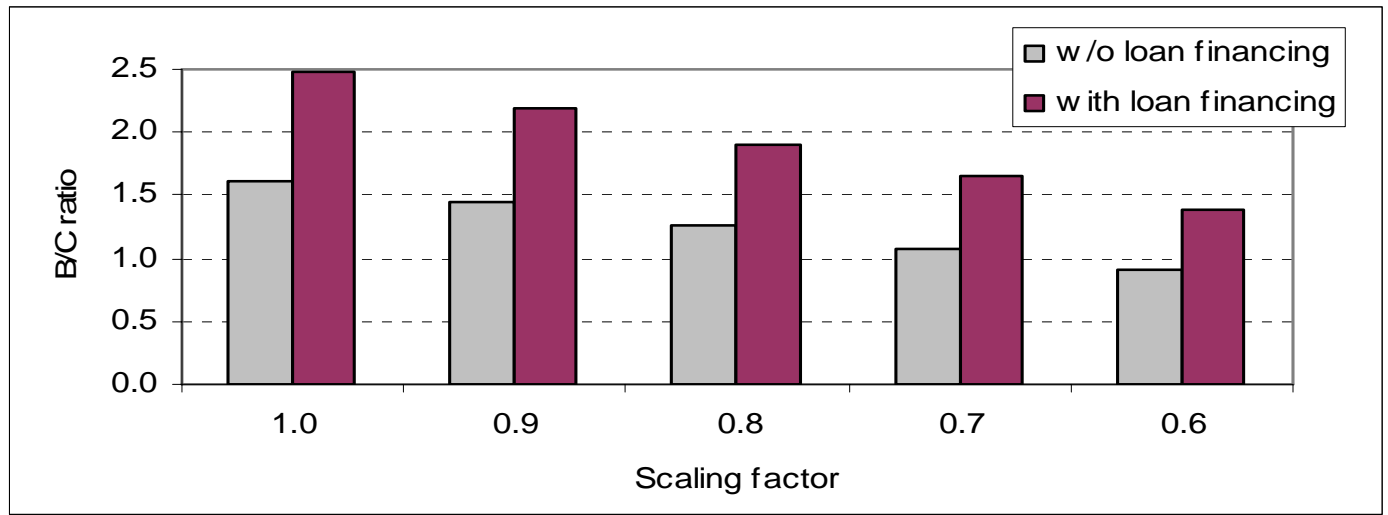

Note: The scaling factor is a multiplier coefficient applied to the average benefits of the risk mitigation project to take into account the uncertainty around these potential benefits.

The net benefits of the structural investments and structural and functions investments are listed in Annex 3. Negative values indicate economically unviable investments for the given time horizon, while positive values indicate an economically viable investment. The projects are economically viable after two years of earthquake exposure with the loan financing program, and after four years without the loan financing program.

While the analysis shows a positive economic rate of return, it should be recalled that municipal investment budgets are limited and that the decision to invest in preparedness and risk reduction activities represents a choice made in an environment of limited resources. The decision to channel funds to disaster mitigation or management should respond to an objective analysis, quantitative at best.

\section{Probabilistic Benefit-cost Ratio of Structural Investments}

The benefits generated by the structural investments are exposed to a high level of uncertainty related to the (very low) frequency and the (potentially very high) severity of an earthquake that would strike Bogotá DC. Unfortunately, the standard cost-benefit analysis, as performed above, relies on average economic values, such as the $\mathrm{B} / \mathrm{C}$ ratio defined as the NPV of the average annual benefits over the NPV of the costs. Therefore, it cannot capture the variability related to the occurrence of a catastrophic event. In particular, these analyses fail to capture much of the information generated by sophisticated earthquake-risk models. 
Such an approach based on average values implicitly assumes that decisionmaker is risk neutral. This assumption is realistic if the government has a large tax base to spread its risk efficiently among the citizens (Arrow and Lind 1970). However, the risk-neutrality assumption claimed by Arrow and Lind may not hold for cities like Bogotá DC, which are highly exposed to large natural disasters. Their tax base may not be large enough to spread catastrophic losses among the taxpayers, and their level of indebtedness may limit their capacity to borrow ex post, thus generating a macroeconomic risk. In this context, the district of Bogotá may act as a risk-averse decisionmaker, where the investment decisions are based not only on the expected values but also on their volatility and the potential extreme values. The policymaker's investment decision is thus based on the distribution of the $\mathrm{B} / \mathrm{C}$ ratio, and not only on its average value.

A probabilistic cost-benefit ratio of the structural investment is derived from the outputs of the earthquake risk model.

The earthquake losses, denoted by the random variable $\tilde{L}$, are defined by the yearly occurrence of an earthquake, denoted by the random variable $\widetilde{P}$ and its severity, denoted by the random variable $\tilde{l}$ :

$\tilde{L}=\tilde{P} \tilde{l}$

where $\widetilde{P}$ follows a Poisson distribution and $\tilde{l}$ follows a Normal distribution. The average number of earthquakes every year is specified by the Poisson parameter $p$, where $p$ is 2 percent, that is, an earthquake occurs every 50 years, on average.

The random annual earthquake losses (before and after structural investment), conditional on the occurrence of an earthquake, are assumed to follow a normal distribution, with an expected value equal to $A A L / p$. The variance of the annual earthquake losses (before and after the mitigation investment) is estimated from the empirical loss exceedance curves generated by the probabilistic earthquake model.

The random earthquake losses (before and after structural investments) are assumed to be stochastically independent over time. This means that the occurrence of an earthquake in a given year does not affect the potential benefits of these investments the following years. This assumption is in fact conservative since the structure of an unretrofitted building after a disaster would be more vulnerable to a new disaster, thus increasing the benefits of structural investments. On the other hand, the correlation between these earthquake losses is assumed perfect. This means that when an earthquake hits the city of Bogotá, potential benefits on (retrofitted or unretrofitted) schools and on (retrofitted or unretrofitted) hospitals and fire stations are perfectly correlated.

The random structural benefits are defined as the difference between the random earthquake losses before structural investment and random earthquake losses after structural investments: 
$\widetilde{B}=\tilde{L}_{w / o}-\tilde{L}_{w}$.

The probabilistic B/C ratio is defined as the NPV of the random benefits (that is, the earthquake losses avoided thanks to the mitigation investment) $\widetilde{B}$ divided by the NPV of the structural investments. The coefficient of variation of the random annual benefits is estimated from the earthquake risk model at 2.5 for structural investments on hospital and fire stations and 2.7 for structural investments on schools.

Figure 8 shows the exceedance probability curve of the probabilistic B/C ratio for structural investments on the portfolio of public assets, with a discount factor of 12 percent and the World Bank financing facility. ${ }^{5}$ The probabilistic $\mathrm{B} / \mathrm{C}$ ratio is higher than unity with a probability of 32 percent, that is, this investment generates an economic rate of return higher than 12 percent with probability 32 percent. There is still a 22 percent probability that the benefits will be three times larger than the structural costs, and the probabilistic $\mathrm{B} / \mathrm{C}$ ratio will exceed 17 with a 1 percent probability. This means that the more severe the earthquake, the more profitable the structural investments. This also means that this structural investment turns out to be economically unviable with a 68 percent probability.

The assessment of the probabilistic distribution function of the B/C ratio, captured through the loss exceedance curve, highlights the high volatility of this ratio. This also illustrates that, although the risk mitigation investment is financially viable on average (that is, the average value of $\mathrm{B} / \mathrm{C}$ ratio is higher than unity), such an investment is in fact non-viable in the most frequent cases where no or low-magnitude earthquakes occur (that is, $\mathrm{B} / \mathrm{C}$ ratio less than unity), while it becomes highly valuable (that is, $\mathrm{B} / \mathrm{C}$ much higher than unity) when high-magnitude earthquakes hit the city.

\footnotetext{
${ }^{5}$ Under these assumptions, the B/C ratio follows a Normal distribution, with expectation equal to 1.60 and standard deviation equal to 1.70 .
} 
Figure 8. Probabilistic Benefit-cost Ratio of Structural Investment, Exceedance Probability Curve

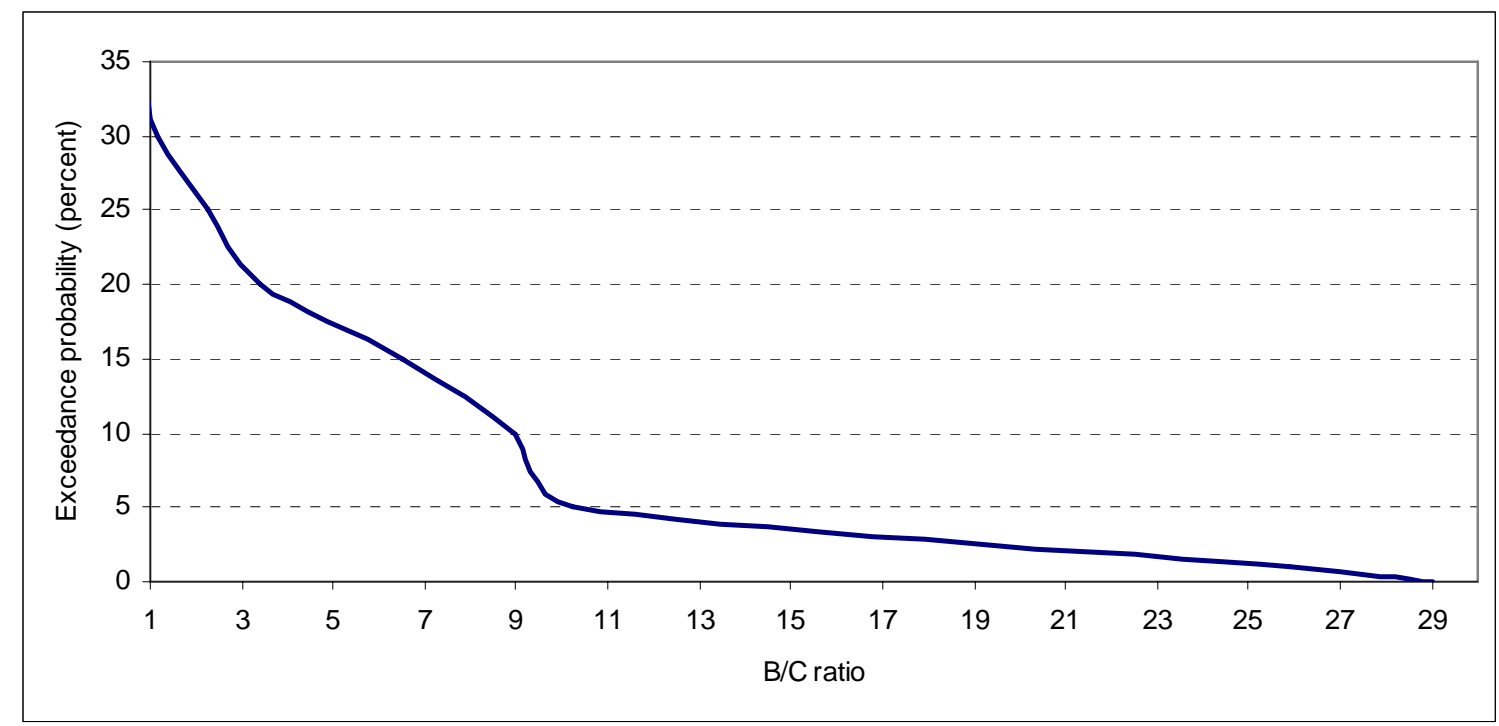

\section{Conclusion}

The World Bank is becoming increasingly involved in mitigation investments related to natural disasters, including those resulting from earthquakes and hurricanes. The World Bank requires from its Borrowers that they conduct a sophisticated cost-benefit analysis to assess whether the proposed investments yield a sufficiently high rate of return.

The cost-benefit analysis of projects exposed to variable benefits has usually been performed using average values. However, such a methodology fails to capture much of the information available and may lead to inappropriate decisions. This paper has presented a probabilistic cost-benefit analysis where economic indicators, such as benefit-cost ratios, are analyzed using risk metrics, including exceedance probability curves. The analysis relies on sophisticated catastrophic risk models that simulate the loss impact of natural disasters on (retrofitted and unretrofitted) buildings.

This analysis has been illustrated using the earthquake vulnerability reduction project of Bogotá District, implemented with the technical and financial assistance of the World Bank. The model has shown that the proposed investments are economically viable, given the country's exposure to earthquakes.

While this methodology relies heavily on the availability of probabilistic catastrophe risk models, it offers a new framework that could be used in a variety of risk mitigation projects financed by the World Bank and other multilateral finance institutions. 
Annex 1. Risk Mitigation Costs (US\$ millions)

\begin{tabular}{|c|c|c|c|c|c|c|c|c|}
\hline \multirow[b]{2}{*}{ Year } & \multicolumn{3}{|c|}{ World Bank Loan } & \multicolumn{3}{|c|}{$\begin{array}{l}\text { Other } \\
\text { Loan }\end{array}$} & \multirow{2}{*}{$\begin{array}{l}\text { Loan } \\
\text { Financing } \\
\text { TOTAL } \\
\text { COST }\end{array}$} & \multirow{2}{*}{$\begin{array}{c}\text { No Loan } \\
\text { Financing } \\
\text { TOTAL COST }\end{array}$} \\
\hline & FEF & CF & Disburs. & Repay. & Disburs. & Repay. & & \\
\hline 1 & 0.40 & 0.00 & 20.00 & 0.00 & 20.00 & 0.00 & 0.40 & 40.00 \\
\hline 2 & 0.00 & 0.21 & 20.00 & 0.00 & 20.00 & 10.02 & 10.23 & 40.00 \\
\hline 3 & 0.00 & 0.14 & 20.00 & 0.00 & 20.00 & 10.02 & 10.16 & 40.00 \\
\hline 4 & 0.00 & 0.07 & 20.00 & 0.00 & 20.00 & 10.02 & 10.09 & 40.00 \\
\hline 5 & 0.00 & 0.00 & 0.00 & 0.00 & 0.00 & 10.02 & 10.02 & 0.00 \\
\hline 6 & 0.00 & 0.00 & 0.00 & 0.00 & 0.00 & 10.02 & 10.02 & 0.00 \\
\hline 7 & 0.00 & 0.00 & 0.00 & 8.66 & 0.00 & 10.02 & 18.68 & 0.00 \\
\hline 8 & 0.00 & 0.00 & 0.00 & 8.66 & 0.00 & 10.02 & 18.68 & 0.00 \\
\hline 9 & 0.00 & 0.00 & 0.00 & 8.66 & 0.00 & 10.02 & 18.68 & 0.00 \\
\hline 10 & 0.00 & 0.00 & 0.00 & 8.66 & 0.00 & 10.02 & 18.68 & 0.00 \\
\hline 11 & 0.00 & 0.00 & 0.00 & 8.66 & 0.00 & 10.02 & 18.68 & 0.00 \\
\hline 12 & 0.00 & 0.00 & 0.00 & 8.66 & 0.00 & 10.02 & 18.68 & 0.00 \\
\hline 13 & 0.00 & 0.00 & 0.00 & 8.66 & 0.00 & 0.00 & 8.66 & 0.00 \\
\hline 14 & 0.00 & 0.00 & 0.00 & 8.66 & 0.00 & 0.00 & 8.66 & 0.00 \\
\hline 15 & 0.00 & 0.00 & 0.00 & 8.66 & 0.00 & 0.00 & 8.66 & 0.00 \\
\hline 16 & 0.00 & 0.00 & 0.00 & 8.66 & 0.00 & 0.00 & 8.66 & 0.00 \\
\hline 17 & 0.00 & 0.00 & 0.00 & 8.66 & 0.00 & 0.00 & 8.66 & 0.00 \\
\hline 18 & 0.00 & 0.00 & 0.00 & 0.00 & 0.00 & 0.00 & 0.00 & 0.00 \\
\hline 19 & 0.00 & 0.00 & 0.00 & 0.00 & 0.00 & 0.00 & 0.00 & 0.00 \\
\hline 20 & 0.00 & 0.00 & 0.00 & 0.00 & 0.00 & 0.00 & 0.00 & 0.00 \\
\hline 21 & 0.00 & 0.00 & 0.00 & 0.00 & 0.00 & 0.00 & 0.00 & 0.00 \\
\hline 22 & 0.00 & 0.00 & 0.00 & 0.00 & 0.00 & 0.00 & 0.00 & 0.00 \\
\hline 23 & 0.00 & 0.00 & 0.00 & 0.00 & 0.00 & 0.00 & 0.00 & 0.00 \\
\hline 24 & 0.00 & 0.00 & 0.00 & 0.00 & 0.00 & 0.00 & 0.00 & 0.00 \\
\hline 25 & 0.00 & 0.00 & 0.00 & 0.00 & 0.00 & 0.00 & 0.00 & 0.00 \\
\hline 26 & 0.00 & 0.00 & 0.00 & 0.00 & 0.00 & 0.00 & 0.00 & 0.00 \\
\hline 27 & 0.00 & 0.00 & 0.00 & 0.00 & 0.00 & 0.00 & 0.00 & 0.00 \\
\hline 28 & 0.00 & 0.00 & 0.00 & 0.00 & 0.00 & 0.00 & 0.00 & 0.00 \\
\hline 29 & 0.00 & 0.00 & 0.00 & 0.00 & 0.00 & 0.00 & 0.00 & 0.00 \\
\hline 30 & 0.00 & 0.00 & 0.00 & 0.00 & 0.00 & 0.00 & 0.00 & 0.00 \\
\hline 31 & 0.00 & 0.00 & 0.00 & 0.00 & 0.00 & 0.00 & 0.00 & 0.00 \\
\hline NPV & 0.40 & 0.35 & 68.04 & 29.17 & 68.04 & 59.50 & 89.42 & 136.07 \\
\hline
\end{tabular}

$\mathrm{FEF}=$ Front-end fees.

$\mathrm{CF}=$ Commitment fees. 


\section{Annex 2. Annual Average Benefits (US\$ millions)}

\begin{tabular}{ccccc} 
& Health & & \multicolumn{2}{c}{ Education } \\
Year & $\mathbf{S}$ & $\mathbf{S + F}$ & $\mathbf{S}$ & $\mathbf{S + F}$ \\
1 & 0.00 & 0.00 & 0.00 & 0.00 \\
2 & 3.83 & 6.56 & 2.89 & 1.54 \\
3 & 7.65 & 13.13 & 5.78 & 3.08 \\
4 & 11.48 & 19.69 & 8.67 & 4.62 \\
5 & 15.31 & 26.26 & 11.56 & 6.15 \\
6 & 15.31 & 26.26 & 11.56 & 6.15 \\
7 & 15.31 & 26.26 & 11.56 & 6.15 \\
8 & 15.31 & 26.26 & 11.56 & 6.15 \\
9 & 15.31 & 26.26 & 11.56 & 6.15 \\
10 & 15.31 & 26.26 & 11.56 & 6.15 \\
11 & 15.31 & 26.26 & 11.56 & 6.15 \\
12 & 15.31 & 26.26 & 11.56 & 6.15 \\
13 & 15.31 & 26.26 & 11.56 & 6.15 \\
14 & 15.31 & 26.26 & 11.56 & 6.15 \\
15 & 15.31 & 26.26 & 11.56 & 6.15 \\
16 & 15.31 & 26.26 & 11.56 & 6.15 \\
17 & 15.31 & 26.26 & 11.56 & 6.15 \\
18 & 15.31 & 26.26 & 11.56 & 6.15 \\
19 & 15.31 & 26.26 & 11.56 & 6.15 \\
20 & 15.31 & 26.26 & 11.56 & 6.15 \\
21 & 15.31 & 26.26 & 11.56 & 6.15 \\
22 & 15.31 & 26.26 & 11.56 & 6.15 \\
23 & 15.31 & 26.26 & 11.56 & 6.15 \\
24 & 15.31 & 26.26 & 11.56 & 6.15 \\
25 & 15.31 & 26.26 & 11.56 & 6.15 \\
26 & 15.31 & 26.26 & 11.56 & 6.15 \\
27 & 15.31 & 26.26 & 11.56 & 6.15 \\
28 & 15.31 & 26.26 & 11.56 & 6.15 \\
29 & 15.31 & 26.26 & 11.56 & 6.15 \\
30 & 15.31 & 26.26 & 11.56 & 6.15 \\
31 & 15.31 & 26.26 & 11.56 & 6.15 \\
NPV & 104.23 & 178.78 & 78.70 & 41.91 \\
& & & &
\end{tabular}

$\mathrm{S}=$ Structural investments.

$\mathrm{SF}=$ Structural and functional investments. 


\section{Annex 3. Annual Average Net Benefits (US\$ millions)}

\begin{tabular}{|c|c|c|c|c|}
\hline \multirow[b]{2}{*}{ Year } & \multicolumn{2}{|c|}{$\begin{array}{c}\text { With } \\
\text { Loan Financing }\end{array}$} & \multicolumn{2}{|c|}{$\begin{array}{c}\text { Without } \\
\text { Loan Financing }\end{array}$} \\
\hline & $S$ & $S+F$ & $S$ & $S+F$ \\
\hline 1 & -0.40 & -0.40 & -40.00 & -40.00 \\
\hline 2 & -3.51 & -2.13 & -33.28 & -31.90 \\
\hline 3 & 3.27 & 6.04 & -26.57 & -23.79 \\
\hline 4 & 10.06 & 14.22 & -19.85 & -15.69 \\
\hline 5 & 16.84 & 22.39 & 26.87 & 32.41 \\
\hline 6 & 16.84 & 22.39 & 26.87 & 32.41 \\
\hline 7 & 8.19 & 13.73 & 26.87 & 32.41 \\
\hline 8 & 8.19 & 13.73 & 26.87 & 32.41 \\
\hline 9 & 8.19 & 13.73 & 26.87 & 32.41 \\
\hline 10 & 8.19 & 13.73 & 26.87 & 32.41 \\
\hline 11 & 8.19 & 13.73 & 26.87 & 32.41 \\
\hline 12 & 8.19 & 13.73 & 26.87 & 32.41 \\
\hline 13 & 18.21 & 23.75 & 26.87 & 32.41 \\
\hline 14 & 18.21 & 23.75 & 26.87 & 32.41 \\
\hline 15 & 18.21 & 23.75 & 26.87 & 32.41 \\
\hline 16 & 18.21 & 23.75 & 26.87 & 32.41 \\
\hline 17 & 18.21 & 23.75 & 26.87 & 32.41 \\
\hline 18 & 26.87 & 32.41 & 26.87 & 32.41 \\
\hline 19 & 26.87 & 32.41 & 26.87 & 32.41 \\
\hline 20 & 26.87 & 32.41 & 26.87 & 32.41 \\
\hline 21 & 26.87 & 32.41 & 26.87 & 32.41 \\
\hline 22 & 26.87 & 32.41 & 26.87 & 32.41 \\
\hline 23 & 26.87 & 32.41 & 26.87 & 32.41 \\
\hline 24 & 26.87 & 32.41 & 26.87 & 32.41 \\
\hline 25 & 26.87 & 32.41 & 26.87 & 32.41 \\
\hline 26 & 26.87 & 32.41 & 26.87 & 32.41 \\
\hline 27 & 26.87 & 32.41 & 26.87 & 32.41 \\
\hline 28 & 26.87 & 32.41 & 26.87 & 32.41 \\
\hline 29 & 26.87 & 32.41 & 26.87 & 32.41 \\
\hline 30 & 26.87 & 32.41 & 26.87 & 32.41 \\
\hline 31 & 26.87 & 32.41 & 26.87 & 32.41 \\
\hline NPV & 93.51 & 131.26 & 46.86 & 84.61 \\
\hline
\end{tabular}

$\mathrm{S}=$ Structural investments.

$\mathrm{SF}=$ Structural and functional investments.

Net benefits $=$ Benefits - costs. 


\section{References}

Arrow, K., and R. Lind. 1970. "Uncertainty and the Evaluation of Public Investment Decisions.” American Economic Review 60(3):364-78.

Boardman, A., D. Greenberg, A. Vining, and D. Weimer. 2001. Cost-Benefit Analysis: Concepts and Practice. Englewood Cliffs, NJ: Prentice Hall.

Cardonna, O. D. 2005. "Definición de la Responsabilidad del Estado, su Exposición ante Desastres Naturales y Diseño de Mecanismo para la Cobertura de los Riesgo Residuales del Estado.” Report prepared for the World Bank.

Cropper, M., A. S. Aydede, and P. Portney. 1992. "Rates of Time Preference for Saving Lives.” American Economic Review (May):469-72.

Jamin, L. 2005. “Estrategia para la Transferencia, Retención y Mitigación des Riesgo Sísmico en Edificaciones Indispensables y de Atención a la Comunidad del Distrito Capital.” Report prepared for the World Bank.

Kleindorfer, P., and H. Kunreuther. 1999. "The Complementary Role of Mitigation and Insurance in Managing Catastrophic Risks.” Risk Analysis 19:727-38.

Mechler, R. 2005. "Cost-Benefit Analysis of Natural Disaster Risk Management in Developing Countries.” Deutsche Gesellschaft fur Technische Zusammenarbeit (GTZ)-funded Working Paper.

Schulze, W., D. Brookshire, R. Hageman, and J. Tscirhart. 1987. "Benefits and Costs of Earthquake Resistant Buildings.” Southern Economic Journal 53:934-51.

Smyth, A. W., G. Altay, G. Deodatis, M. Erdick, G. Franco, P. Gulkan, H. Kunreuther, H. Lus, E. Mete, N. Seeber, and O. Yuzugullu. 2003. "Probabilistic Benefit-Cost Analysis for Earthquake Damage Mitigation: Evaluating Measures for Apartment Houses in Turkey. EERI Earthquake Spectra. 